\title{
Unión Confiteros: militantes socialistas y acción gremial en Buenos Aires a comienzos del siglo XX
}

\author{
Confectionery Union: socialist militants and union activity in Buenos Aires in \\ the first decades of the $20^{\text {th }}$ century
}

\author{
Ludmila Scheinkman*
}

\begin{abstract}
Resumen: Este artículo aborda el desarrollo de la sociedad de socorros mutuos y resistencia Unión Confiteros, que agrupaba a los oficiales confiteros empleados en confiterías y algunas fábricas de la ciudad de Buenos Aires, durante el periodo de hegemonía socialista en la misma (1904-1919). El estudio de este gremio dirigido por militantes socialistas reviste de relevancia, en tanto es un caso pertinente para analizar las "espinosas" relaciones entre el Partido Socialista argentino y el movimiento obrero durante las primeras décadas del siglo XX. Ello nos permitirá mostrar, para este caso, una articulación dinámica entre lucha gremial y lucha política. Emplearemos para el análisis prensa socialista de la época (centralmente La Vanguardia), y el periódico sindical Unión Confiteros.
\end{abstract}

Palabras clave: Partido Socialista, Movimiento Obrero, Argentina, Gremialismo

\begin{abstract}
This article discusses the development of the society of mutual aid and resistance Union Confiteros, which grouped confectionery officers employed in shops and factories of the city of Buenos Aires, and was under socialist hegemony between 1904 and 1919. This case study of a union directed by socialist militants is relevant to analyze the "thorny" relations between the Argentine Socialist Party and the labor movement during the first decades of the 20th century. This will allow us to show, for this case, a dynamic articulation between union activity and political struggles. We will analyze socialist press (La Vanguardia) and the trade union newspaper Unión Confiteros.
\end{abstract}

Keywords: Socialist Party, Labor Movement, Argentina, Unionism

Recibido: $13 / 06 / 2017$

Aceptado: 04/08/2017

\footnotetext{
* Argentina. Doctora en Historia, Universidad de Buenos Aires. Becaria postdoctoral CONICET (Consejo Nacional de Investigaciones Científicas y Técnicas, Argentina). E-mail: ludsch@gmail.com. Este trabajo forma parte de mi investigación doctoral, realizada bajo la dirección de Mirta Zaida Lobato, con el financiamiento de una beca doctoral de CONICET (2012-2017). Una versión preliminar, bajo el título "Unión Confiteros: una estrategia socialista de intervención gremial en las primeras décadas del siglo XX", fue presentada en las VI Jornadas de la División Historia - III Taller de Historia Regional, Universidad Nacional de Luján, 22 y 23 de octubre de 2015. Agradezco la lectura y comentarios de Diego Ceruso, Alejandro Belkin y Hernán Camarero.
}

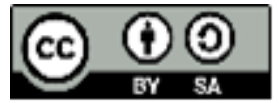




\section{Introducción}

Este artículo aborda el desarrollo de la sociedad cosmopolita de socorros mutuos y mutua protección Unión Confiteros (UC), durante la etapa de conducción socialista en el gremio, entre 1904 y 1919. Esta sociedad agrupaba a los confiteros empleados en las confiterías y algunas fábricas de la ciudad de Buenos Aires, y fue una pequeña organización de socorros mutuos y resistencia. Debido a la hegemonía socialista en la dirección del gremio, en él los militantes de esa orientación desplegaron con amplitud su política de intervención gremial. Por eso mismo, este estudio de caso - que aborda uno de los tres gremios hegemonizados por los socialistas del periodo ${ }^{1}$ - reviste de relevancia, ya que nos permite volver sobre la relación entre el Partido Socialista argentino (PS) y el movimiento obrero durante las primeras décadas del siglo XX.

Varios trabajos han abordado las "espinosas" relaciones entre el Partido Socialista ${ }^{2}$ y el movimiento obrero, señalando que de acuerdo a la estrategia oficial del PS, el movimiento obrero debía ser completamente independiente del partido, y contar con tácticas propias y fines específicos. Esta disociación entre lucha gremial y lucha política habría resultado en un vínculo débil entre el PS y el movimiento obrero ${ }^{3}$. Sin embargo, la

\footnotetext{
${ }^{1}$ En el congreso de concentración de 1914, los socialistas participaron en bloque con tres gremios: la Federación Gráfica Bonaerense, su principal baluarte, la sociedad Unión Confiteros y la Federación fundidores, modelistas y anexos. Otra sociedad liderada tradicionalmente por socialistas en el periodo fue la sociedad de peluqueros. "Movimiento gremial proletario. Congreso de concentración”, LV, 29 de septiembre de 1914.

${ }^{2}$ Sobre la historia del Partido Socialista y el socialismo en Argentina pueden consultarse, además: Jacinto Oddone, Historia del socialismo argentino. Tomo 1, Buenos Aires, La Vanguardia, 1934; Jacinto Oddone, Historia del socialismo argentino. Tomo 2, Buenos Aires, La Vanguardia, 1934; Martín Casaretto, Historia del movimiento obrero argentino, Buenos Aires, Vescovo, 1946; Dardo Cúneo, Juan B. Justo y las luchas sociales en la Argentina, Buenos Aires, Alpe, 1956; José Vazeilles, Los socialistas, Buenos Aires, Jorge Alvarez, 1967; José Ratzer, Los marxistas argentinos del 90, Córdoba, Pasado y Presente, 1969; Francisco Pérez Leirós, Grandezas y miserias de la lucha obrera, Buenos Aires, Libera, 1974; Richard J Walter, The Socialist Party of Argentina, 1890-1930, Austin: Institute of Latin American Studies, University of Texas, 1977; Donald F Weinstein, Juan B. Justo y su época, Buenos Aires, Fundación Juan B. Justo, 1978; Ricardo Falcón, Los orígenes del movimiento obrero (1857-1899), Buenos Aires, CEAL, 1984; Juan Carlos Portantiero, Juan B. Justo: un fundador de la Argentina moderna, Buenos Aires, FCE, 1999; Ricardo Martínez Mazzola, "Campeones del proletariado. El Obrero y los comienzos del socialismo en la Argentina", Políticas de la Memoria. Anuario de investigación e información del CeDInCI 4, 2004, 91-110; Hernán Camarero y Carlos M. Herrera, El Partido Socialista en Argentina: sociedad, política e ideas a través de un siglo, Buenos Aires, Prometeo, 2005; Horacio Tarcus, Marx en la Argentina: sus primeros lectores obreros, intelectuales y científicos, Buenos Aires, Siglo Veintiuno, 2007.

${ }^{3}$ José Aricó, La hipótesis de justo: escritos sobre el socialismo en América Latina (Buenos Aires: Sudamericana, 1999); Hernán Camarero y Alejandro Schneider, La polémica Penelón-Marotta: marxismo y sindicalismo soreliano, 1912-1918, Buenos Aires, CEAL, 1991); Hernán Camarero, "Socialismo y movimiento sindical: una articulación débil. La COA y sus relaciones con el PS durante la década de 1920", Carlos M. Herrera y Hernán Camarero (eds.), El Partido Socialista en Argentina: sociedad, política e ideas a través de un siglo, Buenos Aires, Prometeo, 2005, 185-217; Jeremy Adelman, "El Partido Socialista Argentino", Mirta Zaida Lobato y Juan Suriano (eds.), Nueva Historia Argentina. El progreso, la modernización y sus límites (1880-1916), Buenos Aires, Sudamericana, 2000; María Cristina Tortti, Estrategia del Partido Socialista: reformismo político y reformismo sindical, Buenos Aires, CEAL, 1989; más recientemente, Ricardo Martínez Mazzola, "La neutralidad como problema y como solución. La política gremial del Partido Socialista después de la ruptura sindicalista", Identidades. Revista del Instituto de Estudios Sociales y Políticos de la Patagonia 1, 2011, 1-20, doi:2250-5369; Hernán Camarero, "El Partido Socialista de la Argentina y sus espinosas relaciones con el movimiento obrero: un análisis del surgimiento y disolución del Comité de Propaganda Gremial, 1914-1917”, Izquierdas 22, enero de $2015,158-79$.
}

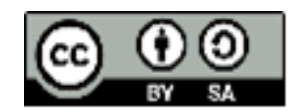


mayoría de estos trabajos han priorizado el análisis de los debates teóricos y posicionamientos estratégicos de la corriente.

En cambio, en estas páginas pretendemos avanzar en la comprensión de este vínculo, a partir del estudio de la intervención concreta de los militantes socialistas en un gremio que dirigieron sin grandes cuestionamientos, lo que les permitió desplegar sin restricciones su estrategia de acción. Ello nos permitirá mostrar, en este caso, una situación diferente: una articulación fuerte entre lucha gremial y lucha política, y una ligazón entre ambas esferas de acción. A través de su intervención, los militantes socialistas en el gremio empalmaron la acción gremial con la línea ideológica y política del partido, y con las campañas emprendidas por éste.

Emplearemos para el análisis prensa socialista de la época (centralmente La Vanguardia, LV), así como el periódico sindical Unión Confiteros (1914-1920). En primer lugar, realizaremos un breve recorrido por la historia del gremio, para luego introducirnos en las acciones entabladas por la sociedad en pos de la conquista del descanso dominical, demanda principal que enarbolaron en las primeras décadas del siglo XX.

\section{La estructura gremial de la Unión Confiteros: entre la resistencia y los socorros mutuos}

Cuando en 1915, al calor de la reorganización gremial y al cumplirse un año del lanzamiento de su periódico, la Unión Confiteros trazaba un balance del año de vida de su hoja de combate y de los últimos años de la organización gremial, este no podía ser más pesimista. "Como todos los años", afirmaban, "contemplamos entristecidos la esterilidad del esfuerzo de un año de labor, pues en él poco o nada puede decirse que se ha adelantado. Las conciencias de los obreros confiteros siguen en el mismo estado de descomposición y sus atrofiados cerebros continúan estancados en sus estrechos conocimientos"4.

Según informaba el periódico, el gremio se había fundado originalmente en Buenos Aires el 7 de marzo de 1879, y funcionaba como "Sociedad cosmopolita de socorros mutuos y mutua protección" para aquellos que practicaban el oficio de confiteros y estaban afiliados a la mutual. La organización agrupaba en su interior a los trabajadores cualificados de las confiterías, y algunas fábricas. Era un ambiente de trabajo masculino, y el de los confiteros fue un oficio de varones. El gremio contaba con una membresía pequeña pero estable, acorde a los niveles de sindicalización del periodo. En marzo de 1914 recibió 164 cotizaciones; en septiembre de 1918, 177, y tuvo en promedio, entre enero de 1914 y septiembre de 1918, 126 cotizantes mensuales ${ }^{5}$. Es decir, no creció ni mermó en el periodo, contando con un grupo estable de adherentes. El acta fundacional de la sociedad,

\footnotetext{
4 "Redacción. Nuestro 36 aniversario", Unión Confiteros, marzo de 1915.

5 "Nómina de los Socios", Unión Confiteros, abril de 1915. Promedio realizado en base a las 52 cotizaciones mensuales disponibles. Unión Confiteros, 7 de marzo de 1914-noviembre de 1918 ( ${ }^{\circ} 1$ a n 50$)$. En marzo de 1914 había recibido 164 cotizaciones; en septiembre de 1918, 177. La afiliación del gremio confitero durante el periodo de reflujo rondó el 10\%; David Rock ha calculado en el momento de mayor afiliación sindical del periodo, a fines de 1918, que esta trepó al 20\%. David Rock, El radicalismo argentino, 1890-1930, Buenos Aires, Amorrortu, 1977, 171.
} 
radicada en Buenos Aires, constataba que 23 confiteros se habían reunido en la importante confitería (luego fábrica) propiedad de don Carlos Colombo, en la calle Cangallo esquina Maipú, para fundar una sociedad de socorros mutuos policlasista, impulsada por los propios patrones $^{6}$. El primer presidente de la asociación fue el mismo Carlos Colombo.

En 1903 se hizo evidente la cercanía de la organización con el socialismo, por su participación en los congresos de la Unión General de Trabajadores (UGT), central de orientación socialista, celebrados en 1903, 1904 y 1905, respectivamente ${ }^{7}$. Serafín Gallofré, dirigente gremial de filiación socialista, fue uno de los impulsores y el dirigente más importantes del gremio en esos años. Como delegado de la UC, integró el Comité Nacional de la UGT, y en 1904 encabezó la Comisión Administrativa de la Cámara de Trabajo impulsada por la UGT ese mismo año ${ }^{8}$.

Cuando, al calor de las huelgas que sacudieron a la ciudad en 1904, se desarrollaron los primeros conflictos en casas del ramo, $L V$ comenzó a seguir asiduamente las actividades y reuniones del gremio. Estos primeros conflictos enfrentaron a los trabajadores de las confiterías con sus patrones, y llevaron a la transformación de la sociedad: de una organización mutual policlasista, que nucleaba por oficio tanto a obreros como a patrones, se transformó en una sociedad de resistencia de clase, integrada por trabajadores. En el mes de octubre de 1904 el gremio declaró la huelga general, y muchas casas obtuvieron mejoras en sus condiciones de trabajo ${ }^{9}$. Es indudable que la actividad socialista contribuyó a esta ruptura entre obreros y patrones, y $L V$ en octubre de 1904 celebró que los confiteros habían "adoptado entusiastamente el principio de la lucha de clases"10. Una crónica societaria publicada en 1916 relataba este proceso:

La sociedad se fundó con un carácter exclusivamente mutualista, figurando entre sus iniciadores patrones, capataces y obreros. En 1904, veinticinco años después de la fundación, los confiteros asociados que sufrían jornadas de trabajo de doce a quince horas cada día hicieron una intensa agitación, para imponer a los patrones condiciones de trabajo más humanas, surgiendo con tal motivo un gran movimiento huelguista. El choque de intereses entre patrones y obreros suscitó hondas y acaloradas

\footnotetext{
6 “Sociedad Unión Confiteros, Pasteleros y Anexos. Fundada el 7 de marzo de 1789”, LV, 22 de marzo de 1916.

${ }^{7}$ Oddone, op. cit., Tomo 2, 117-40. Sobre la historia de la UGT y la CORA, ver: Jacinto Oddone, Gremialismo proletario argentino, Buenos Aires, La Vanguardia, 1949, 121-252; Sebastián Marotta, El Movimiento sindical argentino. Su génesis y desarrollo. Tomo II 1907-1920, Buenos Aires, Lacio, 1961; Hobart Spalding, La clase trabajadora argentina (documentos para su historia-1890/1912), Buenos Aires: Galerna, 1970, 286-311. Sobre el desarrollo de la FORA en su década inicial: Diego Abad de Santillán, La FORA. Ideología y trayectoria del movimiento obrero revolucionario en la Argentina, Buenos Aires, Anarres, 2005; Iaácov Oved, El anarquismo y el movimiento obrero en Argentina, México, Siglo Veintiuno, 1978; Edgardo J Bilsky, La F.O.R.A. y el movimiento obrero (1900-1910), Buenos Aires, CEAL, 1985; Ricardo Falcón, El mundo del trabajo urbano, 1890-1914, Buenos Aires, CEAL, 1986, 83-101; Juan Suriano, Anarquistas: cultura y política libertaria en Buenos Aires, 1890-1910, Buenos Aires: Manantial, 2001.

8 "Unión General de Trabajadores. Cámara de Trabajo", LV, 16 de enero de 1904. La UGT creó la Cámara de Trabajo, como oficina de colocaciones, consultorio médico y asesoría jurídica, y una de sus funciones era controlar el cumplimiento de las leyes obreras. Oddone, op. cit., Tomo 2, 141-44.

9 "En el mundo obrero. Las huelgas", Tribuna, 18 de octubre de 1904.

10 "Las huelgas. Capital. Confiteros", LV, 22 de octubre de 1904.
} 
discusiones en el seno de la organización mutualista, consiguiendo la dirección de la sociedad los oficiales confiteros y expulsando de la misma a los patrones que se opusieron a la declaración de la huelga. Para sostener el movimiento, que más tarde triunfaba en las principales casas, la sociedad acordó destinar de los fondos sociales un subsidio a cada huelguista. Después de esta lucha, la sociedad adquirió el carácter de resistencia sin abandonar por eso el subsidio a los socios en caso de enfermedad ${ }^{11}$.

Los estatutos del gremio fueron modificados en tres ocasiones: en mayo de 1909, en diciembre de 1913 y en mayo de 1917. Los estatutos de 1916 planteaban que el objeto de la sociedad era "reunir en su seno a los operarios de los ramos de confitería, pastelería, facturería y anexos para establecer las más íntimas relaciones entre los asociados y la mutua protección", y cooperar con las sociedades de igual índole de otros oficios "auxiliándolas en las luchas que entablaren con los patrones".

Además, se proponían de modo general "secundar y proteger el desarrollo de las cooperativas y sociedades obreras que se funden con el fin de luchar por el mejoramiento de la clase trabajadora", amparar, defender y proteger a los socios que se vean perseguidos y perjudicados moral o materialmente y "luchar por la elevación intelectual de los mismos". Se establecía asimismo que la sociedad no tenía fines políticos ni religiosos, "siendo prohibido en el recinto social discutir al respecto". Si bien el estatuto de la sociedad no adscribía a ningún credo político -en claro debate con el finalismo anarquista de la FORA V-, el carácter político de la sociedad fue dado, como veremos, por la adscripción socialista de su dirigencia.

Entre sus objetivos, además, buscaba implantar en los talleres las tarifas que acordara la sociedad. Para ello, proponía medios de lucha diversos: ya sea "amigables convenios entre patrones y obreros, ya valiéndose de comisiones encargadas de estudiar y proponer solución a las diferencias entre el capital y el trabajo o acudiendo a los medios que la razón y la experiencia aconsejan". Se propiciaba, por tanto, en primer lugar, el dialogo y el convenio entre patrones y obreros, pero no se descartaban las acciones directas. Sin embargo, no eran el método privilegiado de lucha. Por último, el gremio establecía su solidaridad con el resto de los trabajadores declarando fiesta social el $1^{\circ}$ de mayo, "en que la sociedad participará en los actos que en este día se celebren"12. No especificaba, no obstante, en qué acto participaría, quedando esta definición librada a quien tuviera la dirección del gremio y hegemonizara las asambleas en cada momento.

El gremio además contaba con su propia oficina de colocaciones, que buscaba imponer en los lugares de trabajo el requisito de la afiliación a la sociedad como medida de ingreso al trabajo. La lucha por el control de los ingresos laborales fue característica de estos años, como parte de una lucha mayor frente a los patrones por el control del lugar de

\footnotetext{
11 "Sociedad Unión Confiteros, Pasteleros y Anexos. Fundada el 7 de marzo de 1789", LV, 22 de marzo de 1916.

12 Todas las citas de "Sociedad Unión Confiteros, Pasteleros y Anexos. Fundada el 7 de marzo de 1789", LV, 22 de marzo de 1916.
} 
trabajo. Por medio del manejo de las colocaciones, el gremio buscaba asegurar condiciones de trabajo uniformes evitando la competencia "ruinosa" entre trabajadores.

Además, en 1914 había logrado concretarse una aspiración planteada al menos desde $1911^{13}$. Con el título Unión Confiteros la sociedad comenzó a publicar un periódico mensual de pequeño formato, cuyo objetivo era "informar a los confiteros de la marcha de la organización, y cumple al mismo tiempo una misión de propaganda entre los obreros que todavía no saben apreciar las grandes ventajas que reporta la organización gremial proletaria"14. El periódico cumplía una función pedagógica y educativa, a través de la cual los militantes gremiales buscaban "liderar con el ejemplo, proponiendo un lenguaje, un comportamiento público y una contribución desinteresada a la cultura cívica con el fin de servir como modelo", retomando los términos que Jeremy Adelman y otros autores han usado para describir al PS en general ${ }^{15}$.

Los socorros mutuos y la asistencia a los asociados continuaron siendo una parte importante de la actividad societaria, aunque el reglamento de socorros mutuos sufrió múltiples modificaciones por el enorme peso que los subsidios y asistencias ejercían sobre las finanzas del gremio, siempre escasas por el bajo número de cotizantes ${ }^{16}$. En 1908 una reforma separó las secciones de socorro mutuo y de resistencia, destinando una caja separada a cada una ${ }^{17}$. En 1914 una asamblea decidió volver a unirlas, pero para entonces, la misma existencia de los socorros mutuos comenzó a ponerse en discusión.

El monto de la cotización era relativamente elevado ${ }^{18}$ y los asociados tuvieron constantes dificultades para pagarlo ${ }^{19}$. Esto respondía sin dudas al gran costo de los socorros mutuos que encarecían la cuota social. De acuerdo con el reglamento gremial vigente en 1916, los confiteros asociados, con tres meses cumplidos y pagados en la sociedad, disfrutaban de beneficios como asistencia médica en consultorio o a domicilio, servicio farmacéutico, dentista, oculista, un especialista de garganta, nariz y oídos, baños, subsidios pecuniarios, en caso de fallecimiento servicio fúnebre acompañado con el manto social y subsidios a los socios enfermos ${ }^{20}$.

En 1916, los gastos del sindicato en el socorro a los socios oscilaban en promedio en torno a los $\$ 103,40$ mensuales, y los gastos fijos mensuales eran de $\$ 200$ (\$60 de alquiler

\footnotetext{
13 "Entre un numeroso grupo de obreros confiteros existe el propósito de iniciar la publicación de un periódico gremial, dedicado a propagar entre el gremio las ventajas y beneficios que reporta la asociación", informaba $L V$ en 1911 . "Sociedades gremiales. Los confiteros", $L V$, 9 de diciembre de 1911.

14 “Sociedad Unión Confiteros, Pasteleros y Anexos. Fundada el 7 de marzo de 1789", LV, 22 de marzo de 1916.

${ }^{15}$ Adelman, op. cit., 271. También Aricó, op. cit.; Camarero y Herrera, op. cit.

16 "Socorro mutuo", Unión Confiteros, marzo de 1915.

${ }^{17}$ Unión Confiteros, Pasteleros y anexos, Reglamento de la sociedad cosmopolita Unión Confiteros, Pasteleros y anexos, Buenos Aires, 1909.

${ }^{18}$ La cuota mensual que pagaban los asociados, era de $\$ 1.80$, exigiendo por concepto de ingreso la suma de $\$ 2$ para los menores aprendices de 14 a 17 años y de $\$ 5$ para los adultos de 17 a 50 años. Este monto contrasta con las cotizaciones en la Sociedad de Obreros en Dulce, que en enero de 1919 eran de \$1 para los adultos, y \$0,50 para las mujeres y los menores. Sin dudas los socorros mutuos encarecían la cotización. "Reglamento - Carta orgánica del Sindicato de obreros en dulce afiliado al sindicato", Unión Confiteros, enero de 1919.

19 "Una cualidad característica de este gremio a de ser malos pagadores", se quejaba el tesorero de la sociedad en 1917. "Un mal crónico", Unión Confiteros, febrero de 1917.

20 "Sociedad Unión Confiteros, Pasteleros y Anexos. Fundada el 7 de marzo de 1789”, LV, 22 de marzo de 1916.
} 
del local, \$25 de impresión del periódico, \$100 del haber del delegado y \$15 de gastos telefónicos). Teniendo en cuenta que los ingresos del gremio rondaban, en promedio, los $\$ 275,80$, es posible advertir que el estado financiero del sindicato era delicado. Como había sucedido en 1916, una sucesión de infortunios podía hacer que estos gastos se elevaran rápidamente, poniendo en jaque las finanzas. Tras varios años de crisis económica y con un elevado número de enfermos, el gasto mensual en socorros se había elevado de $\$ 80$ a $\$ 100$ mensuales. Por ello, la sociedad discutió un nuevo proyecto de estatutos y resolvió suprimir el subsidio por enfermedad, sosteniendo la ayuda mutua y la oficina de colocaciones $^{21}$. Dicha reforma se aprobó en enero de 1917, y anuló el subsidio a los enfermos, pese a que los socorros mutuos eran uno de los ejes de la organización gremial de base múltiple levantaba por los socialistas. Esta consistía en una organización estructurada sobre la ayuda y los socorros mutuos, el cooperativismo y otras actividades destinadas a mejorar la existencia de los trabajadores al margen de la lucha reivindicativa ${ }^{22}$. Sostenían los partidarios de esta reforma que, contando la organización con un número relativamente pequeño de asociados, el servicio de socorro a los enfermos era muy caro al sindicato, "pues en la actualidad, con una administración lo más barata posible, se gastan todos los ingresos en los subsidios por enfermedad"23.

Según afirmaban los dirigentes, el gasto en socorros mutuos dificultaba la actividad de resistencia en el gremio, en la medida en que no permitía el ahorro necesario para emprender acciones huelguísticas, que requerían del sostenimiento de los obreros durante la duración de las huelgas para su viabilidad y fortaleza. Por ello los partidarios de la supresión de los socorros indicaban que la reforma permitiría la "reorganización de nuestro descuidado gremio preparándolo para ulteriores luchas" 24 . Esta preocupación por la resistencia, sin embargo, fue a todas luces innecesaria en la medida en que el gremio, durante la etapa de dirigencia socialista, propició una estrategia de acción gremial de carácter político-legalista que, si bien no estaba expresamente en contra de las huelgas, en los hechos no las impulsó ni realizó. El gremio relegó las acciones de tipo huelguísticas y, tras una serie de conflictos fracasados en 1906, no volvió a sostener huelgas hasta fines de 1918. Aunque en el contexto represivo de la década del '10 la viabilidad de las huelgas era escasa, cuando en la posguerra el movimiento obrero se reactivó, el proceso político y la acción obrera rebasaron a la dirigencia socialista, que se mantuvo apegada a las formas legales.

Como han señalado varios autores, el PS sostuvo desde fechas tempranas una posición contraria a las huelgas generales, entendiéndolas como un "mal necesario", producto de las circunstancias sociales. Se trataba de un método "rudimentario" y en buena medida "atrasado" de acción, al que sólo había que recurrir cuando las circunstancias fueran propicias, tras una cuidadosa evaluación y preparación. Las huelgas eran formas de

\footnotetext{
21 "Manifiesto", Unión Confiteros, diciembre de 1916.

22 "Movimiento obrero. La conferencia de anoche", $L V, 20$ de septiembre de 1912.

23 "Sociedad Unión Confiteros, Pasteleros y Anexos. Fundada el 7 de marzo de 1789", LV, 22 de marzo de 1916.

24 "Nuestra Reforma", Unión Confiteros, enero de 1917.
} 
acción "negativa y pasiva", frente a la lucha política que implicaba un "esfuerzo activo"25. Además, se ha señalado que la lucha política consistía básicamente en la lucha electoral, parlamentaria, que habría derivado en un "tibio apoyo a las actividades sindicales"26.

Sin embargo, en el caso del gremio confitero, que fue hegemonizado y dirigido por militantes socialistas que desarrollaron su política con toda amplitud, en el plano gremial la lucha política consistió en una variedad de acciones mucho más amplias que la acción meramente parlamentaria, tendentes a integrar la lucha gremial en la lucha política. De este modo, los socialistas de este gremio buscaron vincular la lucha económica con la lucha política, de una forma que en modo alguno relegó las actividades sindicales, sino que las comprendió de un modo diferente. Para los dirigentes confiteros, la actividad gremial no se reducía a la acción huelguística, y no era esta su principal manifestación; de allí su apoyo a la organización sindical de base múltiple. Como veremos, esto se plasmó a partir de 1905, en la lucha por la efectiva aplicación del descanso dominical en las confiterías del gremio, batalla que duró largos años y ocupó parte importante de la actividad de la asociación, dado que el grueso de su membresía trabajaba en confiterías.

\section{La estrategia de intervención gremial en la lucha por el descanso hebdomadario}

En 1905 se sancionó y reglamentó la Ley 4.661 de descanso dominical, por impulso del diputado socialista Alfredo Palacios ${ }^{27}$. Mientras que en la industria ya era práctica habitual otorgar descanso a los obreros el día domingo, la reglamentación establecía excepciones en lo referente al trabajo en cafés y confiterías, y las mayores violaciones a la norma se dieron en estos establecimientos comerciales y recreativos. Por lo tanto, la sanción de la ley de descanso semanal abrió una batalla por su efectiva aplicación en las confiterías, que duró largos años y fue impulsada por militantes socialistas.

A principios de 1906, a poco de la sanción de la ley, la comisión directiva del gremio confitero denunció ante la policía a aquellas confiterías que violaban la ley de descanso: del Gas, Jockey Club, París, Sudamericana, Pastelería Iris, Los Dos Leones, Antigua Confitería del Sud, La Teatina, Sebastián Sanguinetti y Centro América, entre $\operatorname{otras}^{28}$. El clima en los lugares de trabajo era agitado, y pocos días después de esta

\footnotetext{
${ }^{25}$ Citado en Lucas Poy, "El Partido Socialista y las huelgas: una relación incómoda. Un análisis de las posiciones partidarias en los primeros años del siglo XX", Archivos de historia del movimiento obrero y la izquierda 6, marzo de 2015, 33-35. Sobre la posición del Partido Socialista frente a las huelgas, véase también Adelman, op. cit., 274-77; Alejandro Belkin, "El debate Patroni-Dickmann (1904). Partido y sindicatos en el socialismo argentino", en XI Jornadas Interescuelas/Departamentos de Historia, Tucumán, 2007; Lucas Poy, Los orígenes de la clase obrera argentina. Huelgas, sociedades de resistencia y militancia política en Buenos Aires, 1888-1896, Buenos Aires, Imago Mundi, 2014, 267-308.

${ }^{26}$ Adelman, op. cit., 277. Al respecto, ver también Tortti, op. cit.; Clase obrera, partido y sindicatos: estrategia socialista en los años '30, Buenos Aires, Biblos, 1989; Camarero y Schneider, op. cit; Camarero, "Socialismo...", op. cit.; "El Partido Socialista...", op. cit.

${ }^{27}$ José Panettieri, Las primeras leyes obreras, Buenos Aires, CEAL, 1984, 25-38.

28 "Lo que dicen nuestros lectores. Unión Confiteros", $L V, 29$ de enero de 1906. Esta denuncia causó una pronta reacción en el gremio en la ciudad de Rosario. La sociedad pasteleros y confiteros de dicha localidad invitó a distintos gremios y al
} 
denuncia, detonaron conflictos por motivos de persecución gremial. A mediados de febrero, el patrón de la confitería Los Dos Chinos despidió al capataz de dicho establecimiento por ser, precisamente, el presidente del gremio. De inmediato se produjo una protesta del personal, y tras la inutilidad del reclamo interpuesto por los operarios para obtener la reposición del despedido, se declaró la huelga. El conflicto se extendió cuando los operarios de la confitería del Águila se enteraron de que el dueño de la misma intentaba surtir de masas a Los Dos Chinos. Los empleados resolvieron inmediatamente parar el trabajo, solidarizándose con sus compañeros. La UC convocó entonces a una asamblea para discutir y declarar la huelga general del gremio ${ }^{29}$.

A dicha asamblea concurrieron la "mayoría" de los obreros confiteros. Allí "por entera unanimidad, en vista de que los dueños de confiterías no han querido tomar en consideración el pedido que se les formuló a nombre del gremio, de readmitir al presidente de la sociedad de resistencia en el puesto del cual fue injustamente despedido", se resolvió declarar la huelga general. Durante el transcurso de la misma, los huelguistas se reunieron diariamente a celebrar asambleas en el histórico local socialista de Méjico $2070^{30}$.

Los obreros pasteleros de las más importantes confiterías y fábricas de masas suspendieron el trabajo en solidaridad con sus compañeros de Los Dos Chinos y del Águila. También en asamblea, discutieron un pliego de reivindicaciones que presentaron a los patrones, para aprovechar la contingencia y mejorar sus "actuales pésimas condiciones de trabajo". Según comunicaba $L V$, "la determinación de estos obreros es provocada por la actitud de los patrones que les niegan el descanso dominical a pesar de acordárselo la ley y por el despido del capataz de la confitería "Los dos Chinos", presidente de la sociedad gremial, a quien el patrón puso en la disyuntiva de renunciar a ese puesto o al de operario de la casa"31. El 23 de febrero se informaba que la huelga general proseguía, y que la mayoría de los obreros del gremio se habían plegado al movimiento. Las asambleas, además, eran numerosas y entusiastas, y las pocas confiterías cuyos personales no habían suspendido el trabajo se sumaron al movimiento, agrandando considerablemente las proporciones de la huelga ${ }^{32}$. Como medida de apoyo se aprobó, también por unanimidad, el boicot a las confiterías Jockey Club, del Ribaldi y Gandini, del Águila, La Universal, Buen Gusto, Molino, Continental, Gas, Sud Americana, Solari o Almacén de la Buena Medida, Centro América y Cámpora. La sociedad invitaba a los obreros del gremio y a los trabajadores en general a "apoyar con energía esta medida, cuya mejor aplicación contribuirá sin duda a apresurar la terminación victoriosa del movimiento"33.

centro socialista local a enviar de delegados a una reunión "para proponer que todos los gremios en corporación exijan de los poderes provinciales la sanción del descanso semanal obligatorio", aunque la iniciativa no prosperó. "Correspondencia. Rosario", LV, 30 de enero de 1906; "Correspondencia. Rosario", $L V, 3$ de febrero de 1906.

29 "Las huelgas. Confiteros", $L V, 18$ de febrero de 1906.

30 "Las huelgas. Confiteros", $L V, 22$ de febrero de 1906.

31 "Las huelgas. Pasteleros", $L V, 20$ de febrero de 1906; "Movimiento social. Unión Confiteros", $L V, 21$ de febrero de 1906.

32 "Las huelgas. Confiteros", $L V, 23$ y 24 de febrero de 1906.

33 "Las huelgas. Confiteros", $L V, 25$ de febrero de 1906. 
Durante la semana siguiente continuaron las informaciones de la huelga. Se insistía en que el espíritu de los huelguistas continuaba firme y elevado como el primer día, tal como se manifestaba en las asambleas celebradas diariamente en el local socialista. Los periódicos obreros instaron además al conjunto de los trabajadores a plegarse al boicot a las confiterías mencionadas para apoyar a los huelguistas donde el movimiento era débil, "puesto que parte de los obreros de ellas no se plegaron a la huelga declarada tan justamente", y el boicot se extendió a las confiterías la Ciudad de París, la Universidad del Sud, los Dos Leones y Los Dos Chinos ${ }^{34}$. A pesar de las referencias a la firmeza en la actitud de los huelguistas, el reconocimiento de que los obreros de varias confiterías no se habían incorporado al movimiento, incluyendo la misma en que este se había iniciado, era una expresión de debilidad.

El 4 de marzo se informaba que la huelga del gremio se había declarado parcial, y las referencias a la misma cesaron ${ }^{35}$. Es factible suponer, por lo tanto, que el movimiento terminó en una derrota. Recién hacia mayo volvieron a aparecer noticias sobre la sociedad gremial, pero sin referencia al conflicto ${ }^{36}$. En los años subsiguientes continuó la batalla por la aplicación de la ley. Sin embargo, tras la derrota de las huelgas de 1906, no se volvió a recurrir a este método de lucha. El contexto represivo profundizado tras el Centenario parecía confirmar la visión socialista de las huelgas. Por ello, en años posteriores se desplegó una estrategia consistente en la presión sobre los poderes públicos, y el empleo de todos los mecanismos legales del Estado para conseguir la efectiva aplicación de la ley de descanso, y de modo general, obtener mejoras en las condiciones de trabajo y de vida de los trabajadores. En efecto, en 1909, una comisión de obreros confiteros concurrió a las oficinas del recientemente creado Departamento Nacional del Trabajo (DNT) con el propósito de obtener su concurso en favor de la ley del descanso dominical violada por los patrones del gremio. Si bien los socialistas evaluaban negativamente la acción de dicho departamento, no dejaron de agotar esta instancia de reclamo, y así lo relataban desde las páginas de La Vanguardia:

Como el presidente Matienzo es una personalidad inabordable (cuando por casualidad está en su despacho), los delegados obreros fueron recibidos por el secretario del Departamento, doctor Alejandro Ruzzo. Expuestos los motivos de la visita, el doctor Ruzzo les contestó, que la oficina del trabajo no podía hacer nada al respecto (...). La descepción [sic] fué grande en los comisionados, quienes nos piden dejemos constancia de su protesta por la inutilidad que para ellos resulta aquel carísimo mecanismo del Estado, creado para fines más útiles y concretos de los que desgraciadamente desempeña en estos momentos. (...) Si por la ley se acuerda facultades de inspección a la policía, municipalidad y presidente de la Unión Industrial Argentina, no por esto creemos que el

\footnotetext{
34 "Las huelgas. Confiteros", $L V, 27$ de febrero y 1 de marzo de 1906.

35 "Las huelgas. Confiteros", $L V, 4$ de marzo de 1906.

36 "Movimiento social. Unión Confiteros", LV, 2 de mayo de 1906. Allí se informaba el traslado del local de Chile 1514 a Callao 132.
}

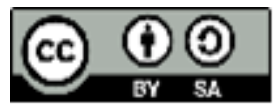


Departamento Nacional del Trabajo deba lavarse las manos, excusándose cada vez que se solicita su colaboración en favor de una ley de moralidad y salud pública como la del descanso dominical ${ }^{37}$.

La denuncia al DNT tenía por objetivo presionar a dicha agencia estatal para que intercediera en favor de los trabajadores. Sin embargo, las denuncias también se radicaron en las dependencias policiales, y la labor de fiscalización de la ley fue emprendida e impulsada por los mismos militantes gremiales.

En agosto de 1911, una nueva reglamentación de la ley estableció la prohibición de vender café y masas los domingos después de las 12 del mediodía. Esta legislación beneficiaba a los trabajadores de confiterías, puesto que los liberaba gran parte del domingo, jornada de mucho trabajo en el ramo. Frente a esto, los dueños de confiterías, cafés, bombonerías, pastelerías y hoteles resolvieron protestar contra la nueva reglamentación con un lock out patronal, cerrando sus negocios el domingo 13 de agosto ${ }^{38}$. Ante la amenaza de los propietarios de prolongar el lock out, la legislación fue modificada nuevamente en su favor ${ }^{39}$. La nueva reglamentación atentaba contra el descanso dominical y por esto mismo, el gremio confitero resolvió enfrentarla con una serie de conferencias de propaganda, cuyo objetivo era generar conciencia entre los confiteros.

La función de esta "activa" campaña de propaganda era no sólo "alcanzar diferentes mejoras en bien de los confiteros, pasteleros, factureros y similares", sino también "fortificar la sociedad", en tanto las conferencias eran empleadas para "elevar" la conciencia de los trabajadores y sumarlos al gremio, y un gremio fuerte permitiría a los confiteros hacer efectivo el descanso semanal. Además, difundieron las conferencias con carteles y lanzaron un breve manifiesto que insistía en la necesidad de fortalecer la sociedad para avanzar en las mejoras ${ }^{40}$ :

Las pésimas condiciones en que trabaja la mayoría de los obreros del gremio son motivo suficiente para que esta institución, creada para el mejoramiento moral y material de los asociados, se dirija a los obreros del ramo invitándolos a ingresar en ella, con el fin de constituir una fuerte potencia que mejore rápidamente el trabajo de los operarios en dulce. Mientras que los obreros de otros oficios dan prueba de actividad y entereza para mejorar sus condiciones, nosotros, debido principalmente a nuestra indiferencia, somos juguetes de patrones y encargados. Ha llegado la hora de demostrar que podemos conseguir el exacto cumplimiento de la ley 4661 que nos conceda el descanso semanal, y que en la actualidad no cumplen los dueños de confitería ${ }^{41}$.

\footnotetext{
37 “El D. N. del Trabajo y los confiteros. Violación al descanso dominical”, $L V, 12$ de agosto de 1909.

38 "El descanso dominical. Nuevas instrucciones del jefe de policía. Los cafés, fondas y almacenes", $L V, 13$ de agosto de 1911.

39 "Descanso dominical. La tercera reglamentación. Las confiterías, cafés, hoteles, restaurants, almacenes, y cigarrerías no cerrarán sus puertas”, $L V, 27$ de agosto de 1911.

40 "Sociedades gremiales. Unión Confiteros", $L V, 25$ de noviembre de 1911.

41 "Sociedades gremiales. Unión Confiteros", $L V, 3$ de diciembre de 1911.
} 
Como la dirección socialista del gremio no consideraba que las huelgas fueran la forma de lucha habitual más deseable, el hincapié estaba puesto en la propaganda: "Confiteros: Concurrid a la conferencia de propaganda para demostrar que tenéis interés por la conquista del descanso hebdomadario", arengaban ${ }^{42}$. Este tipo de apelaciones trazaban un vínculo lógico, natural, casi sin conflictos, entre el fortalecimiento de la sociedad gremial y la consecución de derechos. "Del esfuerzo propio bien orientado depende el mejoramiento de las malas condiciones en que actualmente trabajamos" 43 , afirmaban, y aunque no aclaraban en qué consistía la "buena orientación", podemos suponer que consistía en la agitación política y la demanda legal. La realización de conferencias fue frecuente y continuó en los años siguientes, y en las numerosas charlas convocadas sobre el descanso dominical fue frecuente la participación de oradores socialistas, algunos de ellos con cargos parlamentarios ${ }^{44}$. La forma de "atraer a las filas de la organización a los obreros rehacios [sic] e indiferentes" era realizar disertaciones, distribuir manifiestos, y en suma, "educar a los asociados y fortalecer el espíritu de lucha" 45 .

En una de las conferencias de propaganda gremial, el orador José M. Lemos, quien más adelante sería diputado provincial y secretario general de la Federación Socialista Bonaerense $^{46}$, resumió frente a los confiteros lo que a su juicio debía ser la estrategia socialista de acción gremial. En su discurso afirmó que "era necesario reclamar con insistencia de las autoridades municipales, la higienización de los locales de trabajo; asegurar en la práctica el descanso hebdomadario; apoyar el proyecto Dickmann sobre la jornada de 8 horas y cooperar con el departamento del trabajo en la inspección de las leyes obreras". Por último, cerró su intervención haciendo un llamado a los obreros del gremio para que formasen todos en las filas de la organización, "constituyendo así una fuerza seria para la defensa y mejoramiento del gremio" 47 . Las hojas de $L V$ se hicieron eco muchas veces de estas denuncias a las confiterías con malas condiciones higiénicas y laborales, e incluso realizaron amenazas veladas a los patrones para que las mejoraran ${ }^{48}$.

La acción propagandística, plasmada en la realización de conferencias de finalidad educativa cuyo objetivo era atraer a los obreros al gremio, se combinó con la acción parlamentaria (la propuesta de leyes obreras), y luego con la inspección y la demanda a los poderes públicos para la efectiva aplicación y reglamentación de dichas leyes. Como parte

\footnotetext{
42 "Movimiento obrero. Sociedad "Unión Confiteros". Pro descanso hebdomadario", LV, 14 de septiembre de 1912.

43 "Movimiento obrero. A los obreros confiteros. Pro descanso hebdomadario. La conferencia de esta noche", $L V$, 19 de septiembre de 1912 .

${ }^{44}$ Por ejemplo: "A los obreros confiteros. Por el descanso semanal”, $L V, 18$ de septiembre de 1912.

45 "Movimiento obrero. Unión Confiteros", LV, 6 de agosto de 1913.

${ }^{46}$ Luciano Barandiarán, "La propaganda socialista en el campo bonaerense, 1930-1943", en Actas de las XI Jornadas Interescuelas/Departamentos de Historia, Tucumán, 2007.

47 "Movimiento gremial proletario. La conferencia de anoche", LV, 6 de agosto de 1914.

${ }^{48}$ Por ejemplo: "Del interior. Buenos Aires. Un mal patrón. Bahía Blanca", LV, 19 de diciembre de 1911; "Movimiento obrero. Obreros Confiteros. En la confitería "Las Violetas"", LV, 22 de agosto de 1913; "Movimiento gremial proletario. Obreros confiteros. La higiene en los talleres", $L V, 21$ de enero de 1915; "Movimiento gremial. Noticias varias. Unión confiteros", $L V, 23$ de agosto de 1918.
} 
de la labor de fiscalización del cumplimiento de la legislación obrera, en 1913 los confiteros difundieron entre los asociados al gremio la reglamentación del descanso dominical, acompañando la tarea de inspección y control que desempeñaba el DNT: "El departamento del trabajo envió a nuestra sociedad el texto de la ley del descanso dominical acompañado de una nota en la que recomienda se denuncien a la citada repartición cuantas infracciones se cometan. Toca, pues, a los compañeros todos realizar esa misión tan necesaria para poder disfrutar del descanso los días domingo", reafirmaban, convocando a los trabajadores de base a apropiarse de la labor. La denuncia debía acompañarse con

una intensa campaña de agitación a fin de que los dueños de confiterías respeten la ley número 4661, llamada del descanso dominical, actualmente burlada con descaro en perjuicio de todos nosotros, cumple su deber lanzando a la publicidad esta hoja, para que todos los compañeros se compenetren de la necesidad de preocuparse de nuestra miserable situación y trabajar activamente por el mejoramiento colectivo $^{49}$.

Para acompañar la acción parlamentaria, el gremio realizó también labores de inspección y vigilancia. Por ello los confiteros respondieron positivamente a un llamado realizado el mismo año por Alejandro Unsain, jefe de inspección del DNT, para que las sociedades gremiales colaboraran en la inspección y el cumplimiento de la legislación. La Cámara Sindical de cocineros y pasteleros y las sociedades Oficiales Peluqueros y Unión Confiteros contestaron y ofrecieron su concurso, facilitando al mismo tiempo información. "Gracias a esta cooperación, la ley del descanso dominical comienza a cumplirse en muchas peluquerías que antes trabajaban", sostenían desde $L V$, “y se confía en que pronto será general esa medida"50.

Hasta tal punto llegó la colaboración, que el mismo Unsain asistió en 1914 a una asamblea celebrada por el gremio, "expresamente invitado" por la comisión directiva de la sociedad. La invitación tenía por objeto, según la crónica socialista,

cambiar ideas respecto a la mejor forma de llevar a la práctica la disposición legal que señala el descanso hebdomadario para los obreros confiteros, disposición que en la actualidad burla un buen número de patrones. El doctor Unsain informó a la asamblea sobre las denuncias hechas al departamento por la organización, manifestando que tres de aquellas habían sido comprobadas por los inspectores oficiales. La manera más eficaz - dijo uno de los obreros del gremio- sería obligar a los patrones a poner en un sitio visible de los locales donde se trabaja una lista determinando el día de descanso de cada obrero. El jefe de inspección recogió la observación, que encontró práctica y atinada,

\footnotetext{
49 “Movimiento obrero. Sociedad Unión Confiteros", LV, 7 de agosto de 1913.

50 "Movimiento obrero. Las leyes obreras. La inspección oficial - Hablando con el jefe de la sección - Algunos datos", $L V, 6$ de junio de 1914 .
}

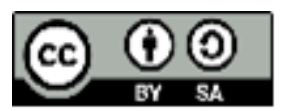


prometiendo transmitirla al presidente del departamento, para los efectos de la reglamentación de la ley del descanso dominical ${ }^{51}$.

Los confiteros continuaron participando en las reuniones de delegados gremiales impulsadas por Unsain, con el objeto de proponer ideas sobre la mejor manera de efectivizar las leyes obreras, realizar denuncias, controlar su avance, y tocar otros puntos relacionados con el trabajo. En cada reunión el jefe de inspección daba cuenta de los avances en los puntos planteados o en las denuncias formuladas en las reuniones anteriores. Allí los confiteros acusaron, por ejemplo, a las confiterías que no cumplían con los pagos salariales, o a las que violaban el día de descanso ${ }^{52}$. Sin embargo, los socialistas juzgaban insuficiente la labor del DNT, y si por un lado denunciaron la falta de inspección de los funcionarios, por otro lado recalcaron la participación y la labor de las sociedades gremiales en la inspección ${ }^{53}$.

El Comité "Pro-reglamentación del trabajo" fue la instancia conformada por la militancia socialista y las organizaciones gremiales para esta tarea de vigilancia. Los domingos, los sindicalistas devenidos inspectores recorrían los establecimientos para comprobar que estuvieran cerrados, lo que constituía asimismo una forma de presionar a las patronales. En estas giras participó Ángel Ugobono, secretario de la sociedad en esos años. Luego de las inspecciones, realizaban las denuncias, y continuaban el seguimiento de las mismas. En sus reuniones, el comité resolvió enviar una nota al DNT "pidiéndole informe si los jueces correspondientes han fallado ya en alguna de las muchas infracciones comprobadas durante los últimos domingos por delegados del comité, pues estos manifiestan no haber sido citados todavía para declarar en los sumarios respectivos" $" 54$. La presión, por lo tanto, se extendía hacia el poder judicial.

Por otro lado, en las reuniones sostenidas en el despacho de la Inspección del DNT desde 1914, Unsain recabó de los representantes gremiales la opinión de los gremios sobre los proyectos del socialista Enrique Dickmann sobre jornada de ocho horas y semana inglesa. El DNT se encargó de enviar copias de los proyectos a los sindicatos, "para que los representantes vengan preparados y traigan la opinión del gremio a este respecto". Esto era de importancia porque "las opiniones que se formulen serán tenidas en cuenta y se hará mención de ellas en el informe que el departamento nacional del trabajo prepara sobre los referidos proyectos del doctor Dickmann"55. En este escenario, $L V$ difundió esta convocatoria del DNT, y la acción colectiva "bien orientada" de los confiteros ${ }^{56}$, que buscaban dirigir la labor gremial hacia el reclamo a los poderes públicos, se plasmó en notas de apoyo al proyecto de jornada laboral presentado por Dickmann durante su

\footnotetext{
51 "Movimiento obrero. La asamblea de los confiteros. Por el descanso hebdomadario", $L V, 12$ de junio de 1914.

52 "Movimiento gremial proletario. En el departamento nacional del trabajo. La reunión de anoche", $L V, 5$ de agosto de 1914.

53 "Inspectores que no inspeccionan", $L V, 13$ de agosto de 1915.

54 "Comité pro reglamentación del trabajo", $L V, 2$ de octubre de 1915.

55 "Movimiento gremial proletario. Las leyes obreras. Reuniones gremiales", $L V, 31$ de julio de 1914.

56 "Movimiento obrero. La conferencia de anoche", $L V, 13$ de agosto de 1913.
} 
diputación ${ }^{57}$. Así se buscó vincular la acción gremial con la presión sobre el DNT y por su intermedio, sobre el parlamento, para apoyar los proyectos socialistas.

En la misma línea, los confiteros se sumaron a la iniciativa de la sociedad de oficiales peluqueros para constituir un comité obrero en la capital encargado de realizar una intensa campaña de agitación, a fin de interesar a las cámaras de diputados y senadores en el inmediato y favorable despacho de los proyectos de semana inglesa mejoras a los empleados y dependientes ${ }^{58}$; impulsaron la formación de un Comité pro derogación de las agencias de colocaciones particulares ${ }^{59}$; y otras iniciativas de este tipo, similares al Comité pro-reglamentación del trabajo, que fueron impulsadas por la militancia socialista en estos años.

Por eso no sorprende que miembros de la comisión directiva del gremio no titubearan en saludar y felicitar al PS por las victorias parlamentarias obtenidas en las elecciones de 1914, en una clara acción partidaria. "Que los nuevos diputados del pueblo, como valientes paladines, en compañía de los diputados Justo y Palacios, luchen con denuedo y con tesón para que las leyes-mordaza de residencia y orden social sean derogadas por completo. Así nosotros, los trabajadores organizados, podremos luchar en nuestro sindicato con más libertad y más entusiasmo", sentenciaba en las páginas de $L V$ Ángel Ugobono, firmando a su nombre en su calidad de presidente de la sociedad de confiteros, en abril del mismo año ${ }^{60}$.

Tan tarde como en 1918, encontramos aún a los confiteros firmando una solicitada, entregada al presidente de la república por una comisión del Centro Dependientes de Almacén de Buenos Aires, en la cual exigían el estricto cumplimiento de la ley de descanso. Más de una década después de la sanción de la ley, la estrategia parlamentaria y legalista de los socialistas, consistente en la propuesta de leyes obreras, las campañas para su aprobación, la fiscalización de su cumplimiento y los reclamos ante las autoridades públicas, habían tenido cuanto menos, en un gremio precisamente socialista, magros resultados. En el marco de esta campaña, el diputado socialista Augusto Bunge interpeló en la cámara de diputados al Ministerio del Interior por el incumplimiento de las leyes obreras. Allí dejó en claro que donde los obreros no tenían fuerza, como en el comercio o en las confiterías, las leyes no se aplicaban ${ }^{61}$. Sin embargo, estos eran precisamente gremios socialistas, que se resistían a interponer medidas de fuerza para la consecución de sus reivindicaciones. 12 años después de la sanción de la ley, tras años de abnegada militancia, la situación de los confiteros no había mejorado mucho. Así lo manifestaba Bunge en la cámara, mientras leía un fragmento de una nota remitida por los confiteros:

\footnotetext{
57 "Movimiento obrero. Jornada legal de trabajo. Los obreros confiteros se adhieren al proyecto del diputado Dickmann", $L V, 6$ de junio de 1914 .

58 "Movimiento gremial proletario. Pro mejoras a los empleados y semana inglesa. Comité de agitación", $L V$, 23 de julio de 1915.

59 "Movimiento gremial proletario. Contra las agencias de colocaciones", $L V, 7$ de julio de 1915.

60 "Nuestro triunfo", $L V, 3$ de abril de 1914.

61 "CAMARA DE DIPUTADOS. La interpelación al ministro del interior”, $L V, 30$ de junio de 1918.
} 
La Unión Confiteros menciona en esta nota toda una serie de denuncias, y dice lo mismo, que ninguna de las denuncias que ha presentado al departamento del trabajo ha sido ni siquiera contestada. "No se cumple la ley dice, por la confitería La Moneda, Corrientes, esquina Pueyrredón, confitería El Molino, Rivadavia 1802; confitería El Cóndor de Oro, Santa Fe 1402; confitería Los Dos Leones, Bernardo de Irigoyen y Brasil; confitería El Tren Mixto, Lima y Brasil; confitería la Sud América, Santa Fe 2402. La gran mayoría de las casas no cumple la ley de descanso dominical". Para estos negocios, la reglamentación acuerda el derecho de estar abiertos el domingo, pero con la obligación del descanso por rotación del personal. "Hace tres años, dice la misma nota, un inspector, acompañado -de un miembro de esta sociedad - parece que el hecho es un acontecimiento muy raro, porque se lo recuerda todavía después de tres años - recorrió varias casas, pero luego esas casas o no cumplieron las órdenes del inspector o volvieron a infringirlas". "Doctor Bunge - dice luego - para ser franco, el departamento nacional del trabajo, y especialmente la sección inspección no goza de la confianza de la clase obrera. Tenemos tanta confianza que en muchos casos no mandamos las denuncias". Dice otra nota que se había ofrecido al departamento nacional del trabajo la cooperación de inspectores "ad hoc" gratuitos, y que nunca fue contestada su proposición. Este es una nota, de la sociedad Unión Confiteros y anexos. Firmada por su secretario, Benjamín Pereyra ${ }^{62}$.

Con ese motivo, y en el marco de la misma campaña, el PS convocó a un mitin en la plaza del Congreso, para pedir al parlamento la aprobación del proyecto Bunge de reforma de la ley de descanso dominical. Hicieron uso de la palabra Arturo Souto, Joaquín Coca y Adolfo Dickmann y el mismo Bunge. Terminado el acto, "una comisión nombrada al efecto" entregó al presidente de la cámara la nota - petitorio, "firmada por más de 30 sociedades obreras", entre las que se contaba, claro está, la Unión Confiteros ${ }^{63} .15$ años de acción societaria en pos de la ley de descanso dominical parecían culminar, de este modo, con un nuevo proyecto de ley, que vendría a zanjar las falencias del primero.

\section{Conclusión}

A lo largo de estas páginas hemos abordado la experiencia de acción de un sindicato, la UC, dirigido sin grandes cuestionamientos por militantes socialistas durante poco más de una década. Este estudio de caso en uno de los pocos gremios hegemonizados por el socialismo en el periodo, nos ha permitido vislumbrar algunas características de su intervención en el plano gremial.

En primer lugar, huelga decirlo, si bien los socialistas consideraban que la acción parlamentaria por la vía del partido político era la instancia superior de acción de los

\footnotetext{
62 Idem.

63 "Pro reforma de la ley de descanso dominical", $L V, 8$ de septiembre de 1918.
} 
trabajadores, no dejaron de participar activamente en los gremios. Pero lo hicieron de una manera que no implicaba el recurso a la huelga como medida central de lucha. La acción sindical debía consistir en impulsar la organización obrera, realizar una activa propaganda gremial, elevar la conciencia de los trabajadores, difundir e impulsar reclamos a los poderes públicos, exigir el cumplimiento de la legislación social y obrera existente e impulsar reformas en dicha legislación. Consideraban asimismo que el gremio no debía embanderarse políticamente, aunque la adscripción política de sus dirigentes fue explícita, y el gremio se vinculó de múltiples y fluidas maneras con la acción parlamentaria de los legisladores del partido.

En la batalla central encarada por el gremio confitero en este periodo, por la aplicación de la ley de descanso dominical, se advierte claramente esta forma de intervención impulsada por los dirigentes gremiales socialistas. Tras la derrota de las huelgas de 1906, se desplegó una estrategia consistente en la presión sobre los poderes públicos, empleando los mecanismos legales del Estado para conseguir la efectiva aplicación de la ley de descanso, y obtener mejoras para los trabajadores. La acción se concentró en la presión sobre el parlamento, el poder ejecutivo, la policía, el DNT e incluso los jueces, y esto implicó la acción combinada de los dirigentes gremiales y los obreros del sindicato con la de los legisladores y abogados socialistas. Esta batalla legal por las conquistas obreras pretendió operar como una vía de organización y movilización de los trabajadores de base.

En ese sentido, en el gremio confitero, la lucha en el terreno político-parlamentario no implicó darle la espalda a la acción gremial. Por el contrario, los dirigentes socialistas confiteros fue canalizaron las demandas de su gremio hacia un terreno de lucha legal, en detrimento de medidas como las huelgas, que fueron de orden secundario y relegadas en función de una lucha más "elevada y culta", que fue juzgada por los socialistas como la verdaderamente transformadora. Esta forma de lucha legalista y parlamentaria, que relegaba las medidas de fuerza como las huelgas frente a las demandas legales y "civilizadas" a los poderes públicos (en las que participaron los dirigentes sindicales junto a los legisladores del partido, mostrando una dinámica articulación entre la acción sindical y la político-parlamentaria), respondía en última instancia al proyecto reformista de avance y evolución gradual e ilustrada plasmado en la hipótesis de Justo ${ }^{64}$.

De este modo, hubo una fuerte articulación e integración entre lucha gremial y lucha política (y entre partido y sindicato), entablada en el marco del "proyecto de corte reformista" del PS, en el que primaba una concepción del socialismo al que se llegaría de forma evolutiva, sin violencia, sin revolución, por vía "civilizatoria"65. Esta misma concepción fue plasmada por los dirigentes sindicales en las formas de lucha gremial, que replicaron las del partido, como es posible advertir en su reticencia al recurso a las huelgas. El mejoramiento de la clase obrera se buscó por la vía de la "obtención de paulatinas

\footnotetext{
${ }^{64}$ Sobre este tema, ver, entre otros, Aricó, op. cit.; Camarero y Schneider, op. cit.; Camarero, op. cit.; Tortti, op. cit.; María Cristina Tortti, Clase obrera, partido y sindicatos: estrategia socialista en los años '30, Buenos Aires, Biblos, 1989.

${ }^{65}$ Aricó, op. cit., 32-71.
}

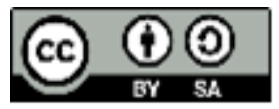


mejoras, logradas dentro de la legalidad vigente, y por la presión ejercida por sus organismos de clase "autónomos" "66. Es probable que, en un contexto de fuerte retroceso del movimiento obrero como el de la década del ' 10 , esta forma de lucha pareciera la más apropiada para los trabajadores confiteros.

\section{Obras citadas}

\section{Libros y artículos}

Abad de Santillán, Diego. La FORA. Ideología y trayectoria del movimiento obrero revolucionario en la Argentina. Buenos Aires: Anarres, 2005.

Adelman, Jeremy. "El Partido Socialista Argentino". En Nueva Historia Argentina. El progreso, la modernización y sus límites (1880-1916), editado por Mirta Zaida Lobato y Juan Suriano. Buenos Aires: Sudamericana, 2000.

Aricó, José. La hipótesis de justo: escritos sobre el socialismo en América Latina. Buenos Aires: Sudamericana, 1999.

Barandiarán, Luciano. "La propaganda socialista en el campo bonaerense, 1930-1943". En Actas de las XI Jornadas Interescuelas/Departamentos de Historia. Tucumán, 2007. https://mundodeltrabajo.files.wordpress.com/2008/01/m061_t02.pdf.

Belkin, Alejandro. "El debate Patroni-Dickmann (1904). Partido y sindicatos en el socialismo argentino". En XI Jornadas Interescuelas/Departamentos de Historia. Tucumán, 2007.

Bilsky, Edgardo J. La F.O.R.A. y el movimiento obrero (1900-1910). Buenos Aires: CEAL, 1985.

Camarero, Hernán. "El Partido Socialista de la Argentina y sus espinosas relaciones con el movimiento obrero: un análisis del surgimiento y disolución del Comité de Propaganda Gremial, 1914-1917". Izquierdas 22 (enero de 2015): 158-79.

. "Socialismo y movimiento sindical: una articulación débil. La COA y sus relaciones con el PS durante la década de 1920". En El Partido Socialista en Argentina: sociedad, política e ideas a través de un siglo, de Carlos M. Herrera y Hernán Camarero, 185-217. Buenos Aires: Prometeo, 2005.

Camarero, Hernán, y Carlos M. Herrera. El Partido Socialista en Argentina: sociedad, política e ideas a través de un siglo. Buenos Aires: Prometeo, 2005.

Camarero, Hernán, y Alejandro Schneider. La polémica Penelón-Marotta: marxismo y sindicalismo soreliano, 1912-1918. Buenos Aires: CEAL, 1991.

Casaretto, Martín. Historia del movimiento obrero argentino. Buenos Aires: Vescovo, 1946.

Cúneo, Dardo. Juan B. Justo y las luchas sociales en la Argentina. Buenos Aires: Alpe, 1956.

Falcón, Ricardo. El mundo del trabajo urbano, 1890-1914. Buenos Aires: CEAL, 1986.

- Los orígenes del movimiento obrero (1857-1899). Buenos Aires: CEAL, 1984.

Marotta, Sebastián. El Movimiento sindical argentino. Su génesis y desarrollo. Tomo II 1907-1920. Buenos Aires: Lacio, 1961.

${ }^{66}$ Tortti, op. cit., 2. 
Martínez Mazzola, Ricardo. "Campeones del proletariado. El Obrero y los comienzos del socialismo en la Argentina". Políticas de la Memoria. Anuario de investigación e información del CeDInCI, núm. 4 (2004): 91-110.

. "La neutralidad como problema y como solución. La política gremial del Partido Socialista después de la ruptura sindicalista”. Identidades. Revista del Instituto de Estudios Sociales y Políticos de la Patagonia 1 (2011): 1-20. doi:2250-5369.

Oddone, Jacinto. Gremialismo proletario argentino. Buenos Aires: La Vanguardia, 1949. . Historia del socialismo argentino. Tomo 1. Buenos Aires: La Vanguardia, 1934. . Historia del socialismo argentino. Tomo 2. Buenos Aires: La Vanguardia, 1934.

Oved, Iaácov. El anarquismo y el movimiento obrero en Argentina. México: Siglo Veintiuno, 1978. Panettieri, José. Las primeras leyes obreras. Buenos Aires: CEAL, 1984.

Pérez Leirós, Francisco. Grandezas y miserias de la lucha obrera. Buenos Aires: Libera, 1974.

Portantiero, Juan Carlos. Juan B. Justo: un fundador de la Argentina moderna. Buenos Aires: FCE, 1999.

Poy, Lucas. "El Partido Socialista y las huelgas: una relación incómoda. Un análisis de las posiciones partidarias en los primeros años del siglo XX”. Archivos de historia del movimiento obrero y la izquierda 6 (marzo de 2015): 31-51.

- Los orígenes de la clase obrera argentina. Huelgas, sociedades de resistencia y militancia política en Buenos Aires, 1888-1896. Buenos Aires: Imago Mundi, 2014.

Ratzer, José. Los marxistas argentinos del 90. Córdoba: Pasado y Presente, 1969.

Rock, David. El radicalismo argentino, 1890-1930. Buenos Aires: Amorrortu, 1977.

Spalding, Hobart. La clase trabajadora argentina (documentos para su historia-1890/1912). Buenos Aires: Galerna, 1970.

Suriano, Juan. Anarquistas: cultura y política libertaria en Buenos Aires, 1890-1910. Buenos Aires: Manantial, 2001.

Tarcus, Horacio. Marx en la Argentina: sus primeros lectores obreros, intelectuales y científicos. Buenos Aires: Siglo Veintiuno, 2007.

Tortti, María Cristina. Clase obrera, partido y sindicatos: estrategia socialista en los años '30. Buenos Aires: Biblos, 1989.

. Estrategia del Partido Socialista: reformismo político y reformismo sindical. Buenos Aires: CEAL, 1989.

Vazeilles, José. Los socialistas. Buenos Aires: Jorge Alvarez, 1967.

Walter, Richard J. The Socialist Party of Argentina, 1890-1930. Austin: Institute of Latin American Studies, University of Texas, 1977.

Weinstein, Donald F. Juan B. Justo y su época. Buenos Aires: Fundación Juan B. Justo, 1978.

Fuentes impresas

La Vanguardia, Buenos Aires, 1904-1919.

Tribuna, Buenos Aires, 1904.

Unión Confiteros, Buenos Aires, 1904-1919.

Unión Confiteros, Pasteleros y anexos, Reglamento de la sociedad cosmopolita Unión Confiteros, Pasteleros y anexos, Buenos Aires, 1909. 